\title{
Long-term monitoring of common spadefoot toad activity in a European steppe using barn owl pellets
}

\author{
Lukas Landler ${ }^{1^{*}}$ (D) and Katharina Stefke ${ }^{2}$
}

\begin{abstract}
Background: One third of the worldwide amphibian species are threatened, therefore, efficient monitoring efforts are needed. Amphibians which adopt a hidden lifestyle, such as the common spadefoot toad, are often missed with standard surveying efforts. Spadefoot toads can be identified in regurgitated pellets of the barn owl, which provides an effective way to estimate toad activity. In our study we analyzed frequency of spadefoot toad remains from 2004 to 2016 in a steppe landscape in eastern Austria.

Methods: We used an automated model selection procedure together with a GLM analysis using a zero inflated error Poisson distribution, to analyze the presence of Pelobates fuscus in barn owl pellets. All analyses were done in the statistical software $R$, and the scripts to reproduce our results are available within this publication. Our approach may provide a template for other researchers to use for their own pellet data.

Conclusions: Our analysis suggested that activity of the common spadefoot toad is mainly influenced by rainfalls, while time of the year and temperature had small but significant effects. Interestingly, our data confirmed the possibility of a second breeding period in summer, triggered by heavy rainfalls. There were no indications for a population decrease in the observed years and locations. Our study shows that barn owl pellets can be used effectivley to assess pelobatid activity in an area. This might constitute a useful monitoring tool for conservation management for amphibians.
\end{abstract}

Keywords: Pelobates fuscus, Seewinkel, Neusiedler See, Amphibian ecology, Yearly activity

\section{Background}

Worldwide amphibians are among the most threatened vertebrate groups and an estimated $1 / 3$ of them are threatened $[1,2]$. In many cases, habitat destruction and degradation, land-use change but also the chytrid fungus are major threats [3-5]. Following the global trend also in Austria, at least half of the native amphibian species are threatened [6]. However, data on the general ecology and seasonal activity of amphibian species is needed, to

*Correspondence: lukas.landler@boku.ac.at

${ }^{1}$ Institute of Zoology, University of Natural Resources and Life Sciences, Gregor-Mendel-Straße 33/I, Vienna 1180, Austria

Full list of author information is available at the end of the article assess extinction risks and population status. Conservation management efforts need to be able to distinguish between inactivity or extinction of a certain taxa at specific locations. For some amphibians, data on ecology and activity are easy to obtain, because such amphibians typically stay in, or close to, their breeding areas most of the year. In contrast, many amphibians live a more discrete life, e.g. staying buried in the soil for most of the year and only being active during favorable conditions. One such example is the common spadefoot toad (Pelobates fuscus), a widespread, however, in Austria critically endangered, pelobatid toad [6]. This toad is threatened by the intensification of agriculture in their remaining habitats, which leads to breeding pond loss and increased

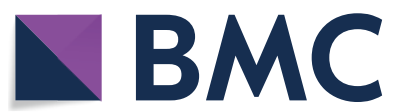

(c) The Author(s) 2021. This article is licensed under a Creative Commons Attribution 4.0 International License, which permits use, sharing, adaptation, distribution and reproduction in any medium or format, as long as you give appropriate credit to the original author(s) and the source, provide a link to the Creative Commons licence, and indicate if changes were made. The images or other third party material in this article are included in the article's Creative Commons licence, unless indicated otherwise in a credit line to the material. If material is not included in the article's Creative Commons licence and your intended use is not permitted by statutory regulation or exceeds the permitted use, you will need to obtain permission directly from the copyright holder. To view a copy of this licence, visit http://creativeco mmons.org/licenses/by/4.0/. The Creative Commons Public Domain Dedication waiver (http://creativecommons.org/publicdomain/ zero/1.0/) applies to the data made available in this article, unless otherwise stated in a credit line to the data. 
use of pesticides [7]. Despite its wide distribution range in Europe, ecological studies are rare. Due to its hidden lifestyle, it can easily remain undetected using standard monitoring procedures [6]. Spadefoot toads are typically night-active and remain buried in the soil during unfavorable conditions.

There has been some discussion concerning the taxonomic status of the spadefoot toads in Europe [8-10]. It has been argued that there is evidence of several cryptic species inside the taxon P. fuscus. The Taxonomic Committee of the Societas Europaea Herpetologica recognized this in their latest assessment and elevated the taxa $b a l$ canicus and vespertinus to the taxonomic rank of a species ([11], see also [12]). Taking this recent change into consideration, the range of $P$. fuscus spans from Denmark in the North to Austria in the South (with a more southern disjunct population in northern Italy) and the Netherlands in the West to the European parts of Russia in the East. Therefore, our study area is located at the south-west border of the $P$. fuscus distribution range and the population belongs to the nominate subspecies $P$. f. fuscus.

Most of the studies on the common spadefoot toads investigate animals at the breeding sites, which is where they can be observed most easily [13-15]. Only very few studies investigated spadefoot toads in their terrestrial habitat [e.g. 16], despite the obvious importance of this habitat type for such a terrestrial toad [17]. In our study we used a novel approach; we investigated barn owl pellets for remains of $P$. fuscus, in order to analyze possible activity patterns of these animals in response to environmental parameters and during the year. It is known that common spadefoot toad individuals are found in barn owl pellets [18], however, systematic analyses focusing on common spadefoot toads are lacking. This is surprising as barn owl pellets have been used for decades as a crude but highly efficient monitoring method of small mammal communities (i.e. mice and shrews) [19]. In fact, the pellets from the presented study were also examined for small mammals, which allowed us to analyze small mammal communities and was published in a separate study [20].

In the current long-term study, we exemplify that barn owl pellet analysis can be used as an efficient method to indicate activity patterns of the common spadefoot toad.

\section{Methods}

\section{Study area}

The study area is located in the East of Austria very close to the Hungarian border, at the East of the Neusiedler See (Fig. 1). This area used to be dominated by a characteristic steppe environment with meadows, however, vineyards and other agricultural land are common at the present time. The area offers rich breeding habitats for amphibians ranging from periodic salt lakes to permanent freshwater ponds and lakes. The region was acknowledged as a world heritage site by the UNESCO in 2001 [21].

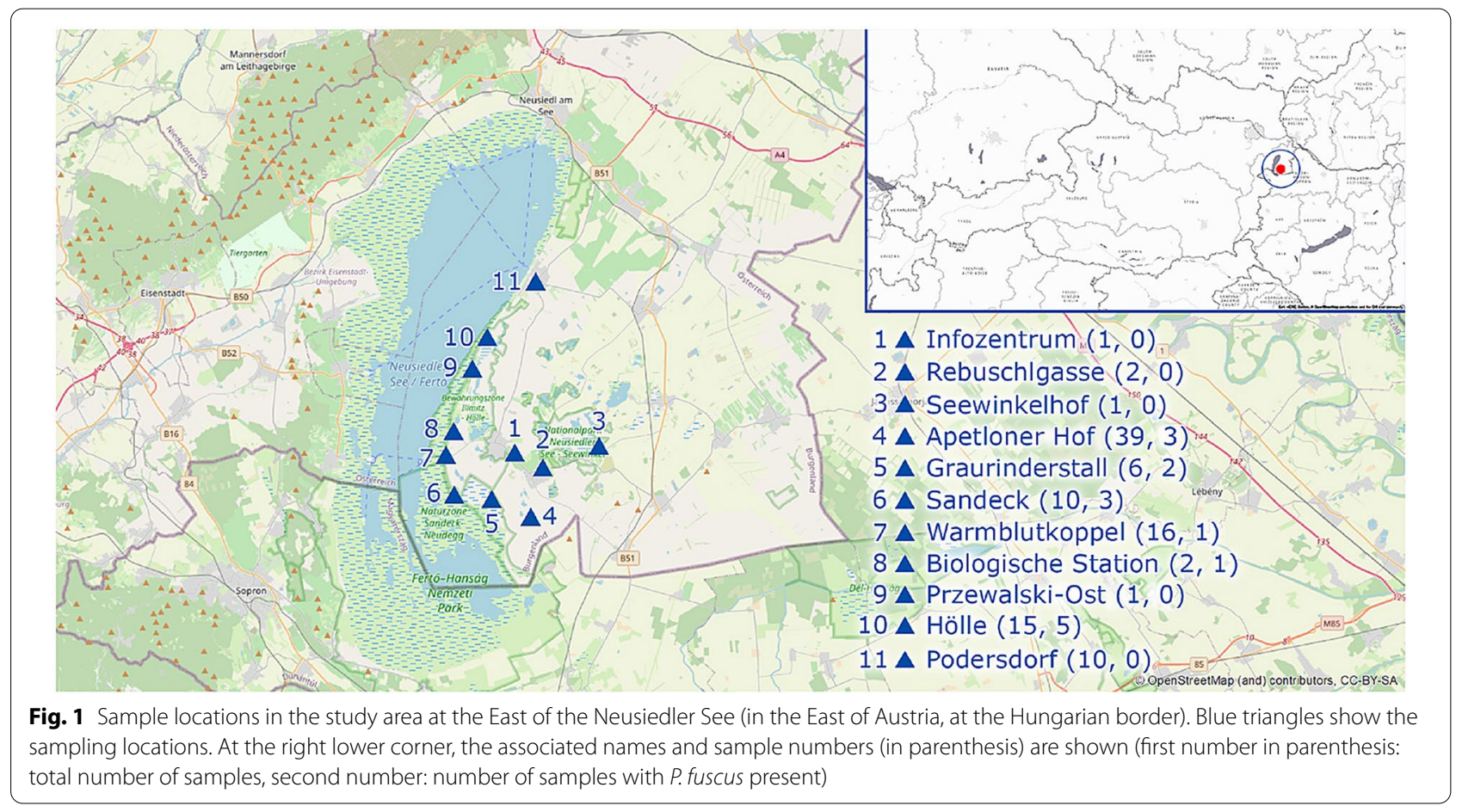




\section{Sample collection and species determination}

We analyzed barn owl pellets from 2004 to 2016 for $P$. fuscus remains. Spadefoot toads are identified by their characteristic tailbones and frontal bones, which makes them easily distinguishable from other vertebrates [22]. Barn owls regurgitate such undigested remains in pellets, which were collected in the study area. The pellets were collected by a ranger (Vinzenz Waba) of the National Park Neusiedler See-Seewinkel who knew the barn owl roost sites. For each collection, all the pellets found at one roost site were combined. One collection trip to one site was therefore regarded as one independent sample. All remains are stored in the Natural History Museum Vienna in the Mammal Collection.

\section{Statistical analysis}

In addition to the data on the number of individuals in the pellets we obtained environmental data from ZAMG (Zentralanstalt Meteorologie und Geodynamik), the national meteorological and geophysical service of Austria (measurements taken from the nearest measuring station: $47^{\circ} 46^{\prime} 21^{\prime \prime} \mathrm{N}, 17^{\circ} 2^{\prime} 0^{\prime \prime} \mathrm{E}, 118 \mathrm{~m}$ above the sea level of Adriatic Sea, $\sim 8 \mathrm{~km}$ from study area). We performed all analyses in R [23], the script and raw data to reproduce the analysis, table and plots are available in the supplementary data (Additional file 2: Data and $\mathrm{R}$ scripts). In order to mathematically describe seasonal (cyclic) patterns throughout the year, we calculated the sine and cosine of the month (in radians, formula used: $\frac{2 \pi}{12} \times$ month (for trigonometric functions see Pewsey et al. [24]). For bi-annual cycles we used the same approach calculating sine and cosine from the doubled radians for each month (later referred to as sine 2 and cosine2). To analyze our data, we used a generalized linear model (GLM) using the function $\operatorname{glmmTMB}$ from the $\mathrm{R}$ package with the same name [25]. We used a Poisson distribution with zero inflation to model our data. We followed an automated model selection paradigm using the function buildglmmTMB (backward model selection based on likelihood ratio test) from the $\mathrm{R}$ package buildmer [26] to avoid overfitting and find the factors contributing to spadefoot toad abundance in the samples (which we assumed to be related to spadefoot toad activity). Our full model included: site, year, sum of precipitation per month, maximum precipitation in $24 \mathrm{~h}$ (in a month), snow (per month), minimum temperature (per month), mean temperature (per month), sine, cosine, sine 2 and cosine 2 as well as all interaction terms. Tables were prepared using the tab_model function in the R package sjPlot [27]. We calculated predictions with $95 \%$ confidence intervals using the function ggpredict from the $\mathrm{R}$ package ggeffects [28]. Plots were prepared using the ggplot function in ggplot2 [29]. For all plots, we converted the trigonometric terms back into months and averaged them, in order to show the relevant effects on a more intuitive scale (e.g. months instead of cosine).

\section{Results and discussion}

The final model, after model selection, included: maximum precipitation in $24 \mathrm{~h}$, cosine, sine 2 , cosine 2 and the interaction between cosine 2 and precipitation (Table 1). Neither site nor year was included in the best model; this suggests that precipitation and the time of the year explained the observed variation in spadefoot toad occurrence better than the sampling year or location. This also means that we have no evidence for location specific $P$. fuscus hot spots nor a decrease or increase in abundance over the years. However, we want to highlight that all of this is based on relatively few toad specimens in the pellet samples (50 total individuals in 103 independent samples). We only observed toads in 4 out of 13 years, possibly suggesting that spadefoot toad activity can fluctuate dramatically between years, presumably based on favorable weather conditions. Hence, direct observation and long-term capture-recapture studies would be needed to gain insights in population dynamics and detect increases or decreases, as it has been successfully done in other studies [e.g. 30].

Our analysis shows very clearly that spadefoot toads were more active (more often found in pellets) around heavy rainfalls (Fig. 2a; Table 1). It is important to note that the rainfall during a single day $(24 \mathrm{~h}$ period) seems more important than the rainfall summed over a month, as the latter was not included in the final model. The dependence on rainfall is known from the literature, however, in our data this dependency seems to be especially striking during summer, while their main breeding season takes place from April to May [31]. Interestingly, it has been observed that spadefoot toads occasionally have a second breeding period in the summer months, in the event of major rainfalls [32]. We assume this is the reason for the interaction between rainfalls and cosine2. In other

Table 1 Results for count model.

\begin{tabular}{lllcr}
\hline Predictors & \multicolumn{4}{l}{ Pelobates fuscus } \\
\cline { 2 - 5 } & Estimate & SE & $\mathbf{z}$ & $\boldsymbol{p}$ \\
\hline Max. Prec. in 24 h & 0.26 & 0.05 & 4.99 & $<0.001$ \\
Cosine (month) & 2.92 & 0.85 & 3.45 & 0.001 \\
Sine2 (month) & -3.97 & 1.19 & -3.32 & 0.001 \\
Cosine2 (month) & -5.16 & 1.55 & -3.32 & 0.001 \\
Mean T (month) & 0.23 & 0.11 & 2.13 & 0.033 \\
Max. Prec. ${ }^{*}$ Cosine2 & 0.14 & 0.05 & 2.91 & 0.004 \\
Observations & 103 & & & \\
\hline
\end{tabular}

Shown are the estimate, standard error (SE), test statistics $(z)$ and $p$-values $(p)$ 

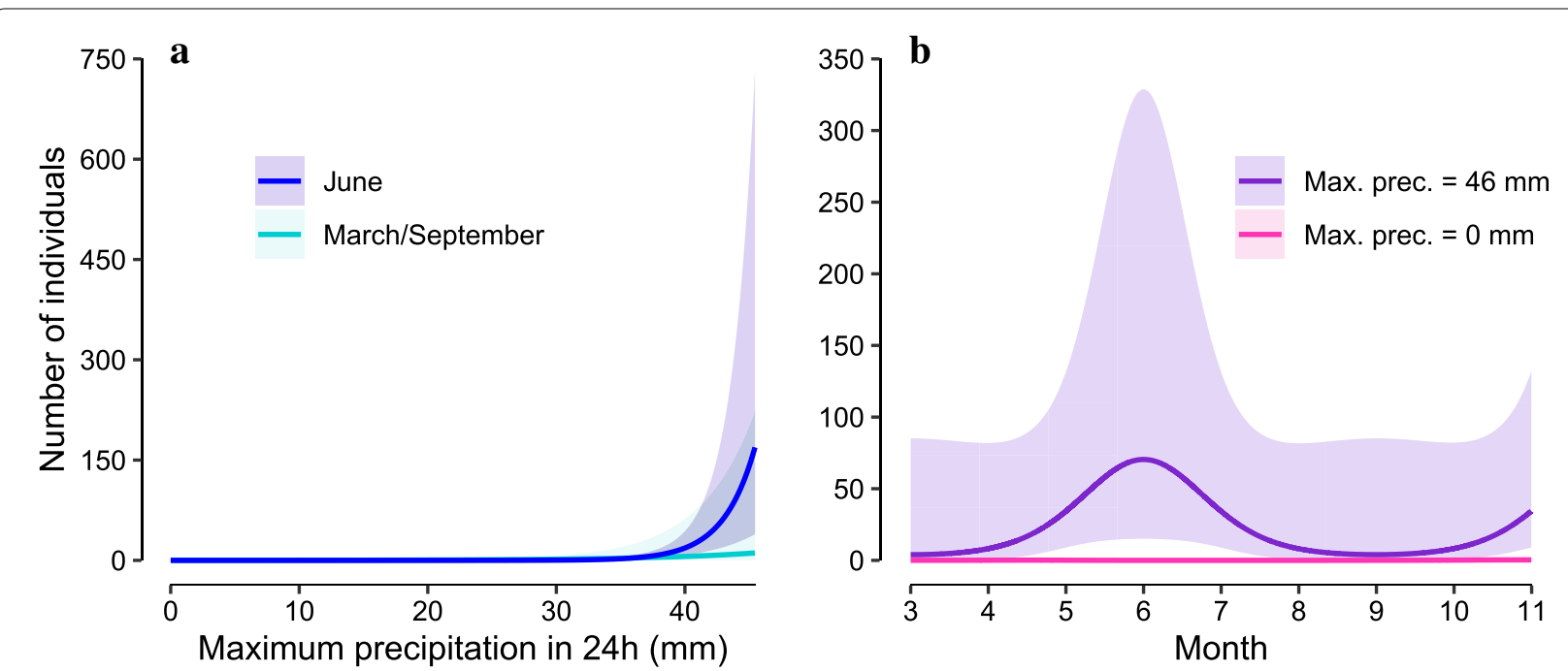

Fig. 2 Model predictions for rain and month effects. Lines indicate the predictions, shaded area the $95 \%$ confidence interval $(\mathrm{Cl})$, ranges of independent variable shown only include values with actual observations. Rain (i.e. maximum precipitation in $24 \mathrm{~h}$ ) had significant main effects on spadefoot toad numbers, however, the effect was strongest in June (a). To visualize the seasonal effects, we back-transformed the trigonometric functions to months and averaged the effects, as well as the Cl. We observed a striking increase of toad activity in June with intense rainfalls (b). Main effects of month and temperature only had minor effects ( $<1$ individuals) on toad activity (see Additional file 1: Fig S1)

words, rainfalls in summer are predicted to lead to high spadefoot toad activity, which is likely indicating breeding activity (Fig. 2b). The main effects of the month show a slightly increased activity in Spring (the typical main breeding season [32, 33]) and Fall; in contrast, if rainfall remains at average levels they predict minimal toad activity in Summer (Additional file 1: Figure S1A). There is a small, but significant, trend of higher toad activity with increasing temperature, if all other factors stay at average levels (Additional file 1: Figure S1B). This is not surprising, as spadefoot toad breeding activity is known to be influenced by temperature [34]. It remains to be seen how climate change will impact spadefoot toad activity (and distribution). Increased temperatures might have minor positive effects, the expected drier conditions, however, will seriously challenge these populations and might lead to a loss of habitable areas for P. fuscus [35].

In conclusion, our analysis shows how pellet data can be used to identify activity patterns of spadefoot toads which have a rather hidden lifestyle. For the common spadefoot toads this method is very applicable, as the species are easily to identify from the remains and cannot be confused with other species and are often missed by other monitoring methods. The only prerequisite needed is an existing owl population. Luckily, the barn owl is a very common and widespread bird species around the world. Considering the effects seen in our study we expect other pellet studies with around 100 samples to be feasible. However, we would encourage newly initiated monitoring efforts to obtain samples regularly around the year, e.g. bi-monthly.
Such regular sampling could increase the resolution of predictions and provide a more detailed account of spadefoot toad activity. The caveat of using pellets is that spadefoot toads only occur at low abundances in such samples, and if no toads are found, no analysis can be performed. Even if spadefoot toads are found in the samples, they will be few. It appears that only peak toad movement activities are represented in such data. In the present study the number of samples was quite different between years $(\mathrm{min}=3$, $\max =18$ ), which is certainly not what we would recommend for future studies. However, linear models including zero-inflation can overcome such inconsistencies as well as low numbers of detections, which are common for data derived from monitoring efforts. Given that pellet studies are still performed and analyzed nowadays and have been for a long time, a lot of pellet samples and data exist. Therefore, including determination of the spadefoot toad, could allow us to easily compare different populations around Europe. Thereby, presence/absence and activity patterns of this rare toad could be compared across different habitat types and pelobatid species.

\section{Supplementary Information}

The online version contains supplementary material available at https://doi. org/10.1186/s40709-021-00133-w.

Additional file 1: Figure $\mathbf{S} 1$. There was still a remaining main month effect (lower activity in the hottest months) after precipitation effects were accounted for, however the effects were very weak $(\mathbf{A})$. Toad abundance in the pellets slightly increased with mean temperature, also here effects were predicted to be very weak $(\mathbf{B})$. 
Additional file 2: Data and R scripts. The original data used and the $R$ script to reproduce our analysis.

\section{Acknowledgements}

We would like to thank Vinzenz Waba, a ranger of the National Park, for collecting barn owl pellets over so many years. In addition, we thank the editor, a reviewer and Sara-Maria Schnedl for valuable comments.

\section{Authors' contributions}

LL analyzed and interpreted data and wrote the paper. KS identified species, prepared data and wrote the paper. Both authors read and approved the final manuscript.

\section{Funding}

LL is supported by the Austrian Science Fund (FWF, Grant Number: P32586).

\section{Availability of data and materials}

All data generated or analyzed during this study are included in this published article and its additional file.

\section{Ethics approval and consent to participate}

There were no ethics nor approval needed for this study.

\section{Consent for publication}

Not applicable.

\section{Competing interests}

The authors declare that they have no competing interests.

\section{Author details}

${ }^{1}$ Institute of Zoology, University of Natural Resources and Life Sciences, Gregor-Mendel-Straße 33/I, Vienna 1180, Austria. ${ }^{2}$ Natural History Museum Vienna, Mammal Collection, Burgring 7, Wien 1010, Austria.

Received: 1 July 2020 Accepted: 7 January 2021

Published online: 12 February 2021

\section{References}

1. Vié J-C, Hilton-Taylor C, Stuart SN. Wildlife in a changing world: an analysis of the 2008 IUCN Red List of threatened species. Gland: IUCN; 2009. 180 p.

2. IUCN. The IUCN red list of threatened species. 2015

3. Becker CG, Fonseca CR, Haddad CFB, Batista RF, Prado PI. Habitat split and the global decline of amphibians. Science. 2007;318:1775-7.

4. Cohen JM, Civitello DJ, Venesky MD, McMahon TA, Rohr JR. An interaction between climate change and infectious disease drove widespread amphibian declines. Glob Change Biol. 2019;25:927-37.

5. Fisher MC, Garner TWJ. Chytrid fungi and global amphibian declines. Nat Rev Microbiol. 2020;18:332-43.

6. Gollmann G. Rote Liste der in Österreich gefährdeten Lurche (Amphibia) und Kriechtiere (Reptilia). In: Rote Listen gefährdeter Tiere Österreichs. Grüne Reihe; 2007. p. 39-62.

7. Cabela A, Grillitsch H, Tiedemann F. Rote Liste ausgewählter Tiergruppen Niederösterreichs-Lurche und Kriechtiere. Amphib Reptil. 1997;1:2.

8. Borkin LJ, Litvinchuk SN, Rosanov JM, Khalturin MD, Lada GA, Borissovsky $A G$, et al. New data on the distribution of two cryptic forms of the common spadefoot toad (Pelobates fuscus) in Eastern Europe. Russ J Herpetol. 2003:10:111-8.

9. Litvinchuk SN, Crottini A, Federici S, De Pous P, Donaire D, Andreone F, et al. Phylogeographic patterns of genetic diversity in the common spadefoot toad, Pelobates fuscus (Anura: Pelobatidae), reveals evolutionary history, postglacial range expansion and secondary contact. Org Divers Evol. 2013;13:433-51.

10. Dufresnes C, Strachinis I, Suriadna N, Mykytynets G, Cogălniceanu D, Székely $P$, et al. Phylogeography of a cryptic speciation continuum in Eurasian spadefoot toads (Pelobates). Mol Ecol. 2019;28:3257-70.

11. Speybroeck J, Beukema W, Dufresnes C, Fritz U, Jablonski D, Lymberakis P, et al. Species list of the European herpetofauna - 2020 update by the
Taxonomic Committee of the Societas Europaea Herpetologica. AmphibReptil. 2020;41:139-89.

12. Dufresnes C, Strachinis I, Tzoras E, Litvinchuk SN, Denoël M. Call a spade a spade: taxonomy and distribution of Pelobates, with description of a new Balkan endemic. ZooKeys. 2019;859:131-58.

13. Van Gelder JJ, Hoedemaekers HCM. Sound Activity and Migration During the Breeding Period of Rana temporaria L, R arvalis Nilsson, Pelobates fuscus Laur. and Rana esculenta L. J Anim Ecol. 1971;40:559-68.

14. Hels T. Population dynamics in a Danish metapopulation of spadefoot toads Pelobates fuscus. Ecography. 2002;25:303-13.

15. Nyström P, Birkedal L, Dahlberg C, Brönmark C. The declining spadefoot toad Pelobates fuscus: calling site choice and conservation. Ecography. 2002:25:488-98.

16. Jahn K. Beobachtungen zur Eingrabetiefe von Pelobates fuscus während der Laichzeit. Z Für Feldherpetologie. 1997;4:165-72.

17. Carisio L, Sacchi R, Seglie D, Sindaco R. Habitat selection in the fossorial toad Pelobates fuscus insubricus (Amphibia: Pelobatidae): does the soil affect species occurrence? Acta Herpetol. 2014;9:51-9.

18. Roulin A, Dubey S. Amphibians in the diet of European barn owls. Bird Study. 2013;60:264-9.

19. Avenant NL. Barn owl pellets: a useful tool for monitoring small mammal communities. Belg J Zool. 2005;135:39-43.

20. Stefke K, Landler L. Long-term monitoring of rodent and shrew communities in a biodiversity hot-spot in Austria using barn owl (Tyto alba) pellets. Acta Oecol. 2020;109:103660.

21. Csaplovics E. Der Schilfgürtel des Neusiedler Sees. Österr Wasser- Abfallwirtsch. 2019;71:11-2.

22. März R, Banz K. Gewöll- und Rupfungskunde. 3rd ed. Berlin: Akademischer Verlag; 1987.

23. R Core Team. R: A language and environment for statistical computing. Vienna: R Foundation for Statistical Computing; 2020.

24. Pewsey A, Neuhäuser M, Ruxton GD. Circular statistics in R. Oxford: University Press; 2013.

25. Brooks ME, Kristensen K, van Benthem KJ, Magnusson A, Berg CW, Nielsen A, et al. glmmTMB balances speed and flexibility among packages for zeroinflated generalized linear mixed modeling. R Journal. 2017;9:378-400.

26. Voeten CC. Buildmer: stepwise elimination and term reordering for mixedeffects regression. 2020. https://CRAN.R-project.org/package=buildmer.

27. Lüdecke D. sjPlot: data visualization for statistics in social science. R package version 2.8.3; 2020.

28. Lüdecke D. ggeffects: Tidy data frames of marginal effects from regression models. J Open Source Softw. 2018:3:772

29. Wickham H. ggplot2: elegant graphics for data analysis. Berlin: Springer; 2016.

30. Jehle R, Hoed I W, Thonke A. Structure and dynamics of central European amphibian populations: a comparison between Triturus dobrogicus (Amphibia, Urodela) and Pelobates fuscus (Amphibia, Anura). Aust J Ecol. 1995;20:362-6.

31. Yermokhin MV, Tabachishin VG, Ivanov GA. Spawning migration phenology of the spadefoot toad Pelobates fuscus (Pelobatidae, Amphibia) in the valley of the Medveditsa River (Saratov oblast). Biol Bull. 2015:42:931-6.

32. Sacher P. Mehriährige Beobachtungen an einer Population der Knoblauchkröte (Pelobates fuscus). Hercynia-Ökol Umw Mitteleur. 1987;24:142-52

33. Eggert C, Guyétant R. Reproductive behaviour of spadefoot toads (Pelobates fuscus): daily sex ratios and males'tactics, ages, and physical condition. Can J Zool. 2003;81:46-51.

34. Nicoara A, Nicoara M. Surveying an isolated population of Pelobates fuscus (Anura, Amphibia) in the urban area of the town of lasi (Romania). Oceanol Hydrobiol Stud. 2008;37:61-9.

35. D'Amen M, Bombi P, Pearman PB, Schmatz DR, Zimmermann NE, Bologna MA. Will climate change reduce the efficacy of protected areas for amphibian conservation in Italy? Biol Conserv. 201 1;144:989-97.

\section{Publisher's note}

Springer Nature remains neutral with regard to jurisdictional claims in published maps and institutional affiliations. 